biomarkers for primary and secondary OA, respectively, when compared with healthy individuals. TNF- $\alpha$ is a suitable biomarker for the diagnosis of both primary and secondary OA when compared to SLE patients, whereas IL- 6 and IL-1 $\beta$ were apparent explicit markers of primary $\mathrm{OA}$, while $\mathrm{IL}-10$ was exclusive for secondary OA.

Abstract AB1379 - Table 1. lists the values obtained from the ROC curves for the cytokine panel and NOx for patients clinically diagnosed with primary and secondary osteoarthritis against normal healthy controls.

\begin{tabular}{|c|c|c|c|c|c|c|c|c|}
\hline & \multicolumn{4}{|c|}{ Primary $\mathrm{OA}$} & \multicolumn{4}{|c|}{ Secondary $\mathrm{OA}$} \\
\hline & $\begin{array}{l}\text { AUC } \\
(\%)\end{array}$ & $\begin{array}{l}\text { Cut-off } \\
\text { value }^{*}\end{array}$ & Sensitivity & Specificity & $\begin{array}{c}\text { AUC } \\
(\%)\end{array}$ & $\begin{array}{l}\text { Cut-off } \\
\text { value }^{*}\end{array}$ & Sensitivity & Specificity \\
\hline $\begin{array}{l}\text { TNF- } \\
\alpha\end{array}$ & 88.3 & $>10.8$ & 93.33 & 80.00 & 97.0 & $>28.2$ & 100.00 & 96.67 \\
\hline IL-10 & 88.6 & $>32.67$ & 85.71 & 92.59 & 93.1 & $>32.67$ & 90.00 & 92.59 \\
\hline IL-6 & 59.3 & $>3.98$ & 89.66 & 40.74 & 81.2 & $>12.02$ & 66.67 & 96.15 \\
\hline IL-1 $1 \beta$ & 85.2 & $>1.18$ & 96.43 & 68.42 & 61.4 & $>0.88$ & 77.78 & 57.89 \\
\hline NOx & 72.0 & $>18.89$ & 93.33 & 60.71 & 73.0 & $>18.89$ & 100.00 & 60.71 \\
\hline
\end{tabular}

${ }^{\star}$ For the cytokines, in $\mathrm{pg} / \mathrm{ml}$ and for $\mathrm{NOx}$ in $\mu \mathrm{mol} / \mathrm{l}$

Conclusions: This preliminary study suggests that higher levels of inflammatory cytokines are present in secondary OA compared to primary OA. Furthermore, distinct markers for primary and secondary $O A$ were identified, indivative of the potential for developing different therapeutic agents for the different types of OA. Acknowledgements: The authors acknowledge the University of Colombo, Sri Lanka for funding.

Disclosure of Interest: None declared

DOI: 10.1136/annrheumdis-2018-eular.6602

\section{AB1380 PERIPHERAL NEUROPATHY IN INFLAMMATORY JOINT DISEASES}

Y. Yehudina ${ }^{1}$, O. Syniachenko ${ }^{2}$, T. Bevzenko ${ }^{3} .{ }^{1}$ internal Medicine, Dnepropetrovsk Medical Academy, Dnipro; ${ }^{2}$ Donetsk Medical University, Lyman; ${ }^{3}$ Shupyk National Medical academy, Kyiv, Ukraine

Background: For frequent extra-articular (systemic) manifestations of joints inflammatory diseases are various damage of the nervous system, ${ }^{2}$ and the presence and severity of peripheral neuropathy (PNP) have significance in the clinical course, which incidence among these patients is $5 \%-10 \% .{ }^{1}$ Nevertheless, many clinical and pathogenic aspects of this peripheral neuropathy (PNP) remain obscure.

Objectives: to evaluate the rate and clinical features of PNP in rheumatoid arthritis (RA), chlamydia urogenital reactive arthritis (ReA), psoriatic arthritis $(P A)$ and ankylosing spondylitis (AS), to examine the issues of pathogenetic constructions such changes of the nervous system, define risk factors.

Methods: The study included 416 patients with inflammatory joint diseases, among them 131 RA patients, 101 ReA, 76 PA and 108 AS. The average age of the examined was respectively $45,32,42$ and 38 years, disease duration $-10,4$, 12 and 11 years, male to female ratio $-1: 5,1: 1,1: 2$ and $10: 1$

Results: The frequency of the PNP in RA, ReA, PA and AS was 13\%, 19\%, 24\% and $34 \%$, while its severity in patients with $P A<R e A<R A<A S$, and the same type ratio of motor, sensory and mixed disorders of inflammatory joints diseases, trophic, visceral and vascular vegetative changes, the connexion with the male sex, the activity of arthritis and the presence of tendovaginitis, participation of immune disorders, endothelial dysfunction of blood vessels and changes in physical and chemical rheological viscoelastic properties of blood in the pathogenesis constructions of the nervous system lesions are united around. ReA and PA are different by frequency of hands and feet distal pathology, the AS - by the beginnings of tunnel syndrome. RA tends to impact on the PNP digital arteritis, myositis, eye disease, and Sjogren's syndrome, ReA - on sacroilitit, PA - on exudative form of cutaneous psoriasis, AS - on eye disease, at that, the risk factors for severe course of neuropathy in RA is considered to involve in the process of elbows, $R e A$ - intervertebral and facet joints, PA - wrist, AS - sacroiliac. Guillain-Barré syndrome develops respectively in $3 \%, 4 \%, 5 \%$ and $9 \%$ of patients with RA, PA, ReA and AS, or in $24 \%, 17 \%, 26 \%$ and $27 \%$ cases of PNP, which is closely linked to the presence of tendovaginitis in all inflammatory diseases and severity of articular syndrome, in RA it depends on the presence of hypothyroidism, in ReA - on nephropathy and violations of the heart's electrical conduction, in AS - on osteoporosis, and seropositive for anti-cyclic citrullinated peptide antibody is a risk factor for such peripheral nervous system disorders.

Conclusions: PNP is a relatively common manifestation of inflammatory diseases of the joints, which correlate with clinical and laboratory signs of the disease, and in the future such active detection of the nervous system pathology will be useful for timely follow-up rehabilitation.

\section{REFERENCE:}

[1] Oomatia A., Fang H., Petri M., Birnbaum J. Peripheral neuropathies in systemic lupus erythematosus: clinical features, disease associations, and immunologic characteristics evaluated over a twenty-five-year study period. Arthritis Rheumatol 2014;66(4):1000-1009.

[2] Sampaio-Barros PD. Epidemiology of spondyloarthritis in Brazil. Am. J. Med. Sci 2011;341(4): 287-288.

Disclosure of Interest: None declared

DOI: 10.1136/annrheumdis-2018-eular.3736

\section{Education}

\section{AB1381 FOUR ANNUAL INTERNATIONAL DIFFERENT MEETINGS OF RHEUMATOLOGY: COMPARATION OF THE CONTENTS, ANALYSIS, CHALLENGE AND OPORTUNITIES}

A.J. Pedro ${ }^{1}$, E. Cuevas ${ }^{1}$, C. Abud ${ }^{1}$, R. Moreno ${ }^{1}$, M. Martinez ${ }^{1}$, D. Herrera ${ }^{1}$ E. Acevedo ${ }^{2}$, H. Lopez ${ }^{2}$, D. Ramos ${ }^{2}$, G. Aguilera Barragan², G. Martinez ${ }^{2}$,

T. Luna ${ }^{2}$, E. Santillan ${ }^{2} .{ }^{1}$ Rheumatology; ${ }^{2}$ Hospital Central Ignacio Morones Prieto, San Luis Potosí, Mexico

Background: The medical meetings are a tool to help us be able to escalate and actualize the medical knowledge and their quality is a responsibility of Colleges and Institutions.

Objectives: To assess the academic level of four types of different annual Meeting of Rheumatology

Methods: We used as support information the summaries published in the sup plements of the journal Reumatologia Clinica, SE1 Vol. 12 of February 2016, the supplement SE 1 Vol. 13 of February 2017, the application for electronic media of the ACR/ARHP 2016 of the American Congress of Rheumatology 2016 and the website for abstracts of ,EULAR 2017 dedicated to the surveys presented in the XLIV Mexican Congress of Rheumatology, XLV Mexican Congress of Rheumatology and the 2016 ACR/ARHP Annual Meeting, and EULAR 2017 respectively, of each survey we was obtained information about of the diverse pathologies, the type of trial, content and population referred (adults versus children).

Results: $275,340,3275$ and 4129 were presented in the XLIV Mexican Congress of Rheumatology, XLV Mexican Congress of Rheumatology, the 2016 ACR/ARHP Annual Meeting and EULAR 2017 respectively. Rheumatoid arthritis (RA) was the most common pathology with 23\%, 26\%, 21\% and 27\% in CMR 44, CMR 45, ACR 2016 and EULAR 2017 respectively, followed by systemic lupus erythematosus, third place was vasculitis, beside in international congress was the spondyloartrhitis Highlighted, RA the items about of clinic manifestations were accounted for almost $30 \%$ in the Mexican congress and almost $20 \%$ in ACR and EULAR.

Observational studies accounted for almost $40 \%$ in Mexican congresses vs. $33 \%$ in ACR 2016 and $55 \%$ in, EULAR 2017 beside surveys about of basic research were minimal in Mexican congress, but in ACR 2016 accounted for $21 \%$ and $12 \%$ in EULAR 2016

The trials about of Paediatric Rheumatology were $12.3 \%, 5.5 \%$ and $4.9 \%$ in CMR 44, CMR 45 and ${ }^{\text {ACR } 2016}$ respectively.

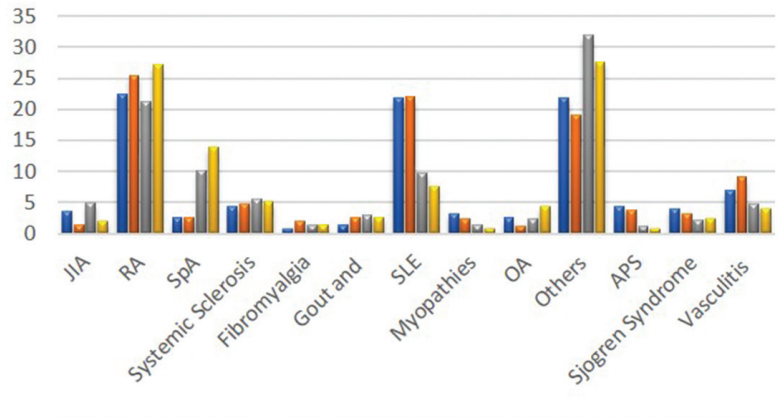

घCMR 44 घCMR 45 घ2016 ACR/ARHP Annual Meeting घEULAR 2017

Abstract AB1381 - Figure 1. percentage of rheumatic disease

Conclusions: Rheumatology Meeting constitutes a support to obtain the adequate medical knowledge based in evidence, in this important branch of 
Medicine. We require of the collaborative efforts to achieve best goals with controlled studies, clinical and basic assays, increasing the Meeting's quality.

\section{REFERENCES:}

[1] Serrano KJ, Yu M, Riley WT, Patel V, Hughes P, Marchesini K, Atienza AA. Willingness to Exchange Health Information via Mobile Devices: Findings From a Population-Based Survey. Ann Fam Med. 2016 Jan-Feb;14 (1):34-40. doi: 10.1370/afm.1888.

[2] Studdert DM, Mello MM, Gawande AA; Ghandi TK, Kachalia A, Yoon C, et al. Claims, Errors, and Compensation Payments in Medical Malpractice Litigation. N Engl J Med 2006;354:2024-33.

[3] Bothwell LE, Greene JA, Podolsky SH, and Jones DS. Assessing the Gold Standard-Lessons from the History of RCTs. N Engl J Med 2016; 374:2175-81.

[4] Fiore LD and Lavori PW. Integrating Randomized Comparative Effectiveness Research with Patient Care. N Engl J Med 2016; 374:2152-8.

Disclosure of Interest: None declared

DOI: 10.1136/annrheumdis-2018-eular.7052

\section{AB1382 HOW EFFECTIVE IS POSTGRADUATE TRAINING IN THE RHEUMATOLOGY DEPARTMENT OF A TEACHING HOSPITAL?}

A. Paul ${ }^{1}$, C. Bennett ${ }^{2} .{ }^{1}$ Rheumatology, South Tees Hospitals NHS Foundation Trust, Middlesbrough; ${ }^{2}$ Division of Health Sciences, The University of Warwick, Coventry, UK

Background: Rheumatological disorders are very common in primary ${ }^{1}$ and secondary care. ${ }^{2}$ Each year, $20 \%$ of the general population consult their Genera Practitioner (GP) due to a musculoskeletal problem. ${ }^{3}$ With demands on musculos keletal service likely to rise further, there is a growing concern that new doctors of tomorrow may not be equipped with necessary competencies to deal with this burden. $^{4,5}$

Objectives: To explore the effectiveness of rheumatology departmental induction training. To explore the confidence of post-graduate trainees in assessing and managing patients with rheumatological conditions. To evaluate the confidence of post-graduate trainees to do knee aspiration and injection. To explore the satisfaction of post-graduate trainees and trainers with various teaching activities in the department. To make recommendation for further improvement of the quality of on-the-job teaching of junior doctors posted in the department of rheumatology. Methods: An online questionnaire survey was administered to all current and previous four years' rheumatology trainees. Subsequently trainees were interviewed divided in to two focus groups for Specialty Trainees and non-specialist (General Practice and Foundation Year 2) trainees. Consultants, Allied Health Professionals and nurses were also interviewed divided in to two focus groups. The data from questionnaire survey and qualitative data from focus group interviews was then analysed and collated.

Results: Induction was suboptimal with only two-thirds of trainees rating its quality as excellent or good. Most trainees were confident in the assessment and management of rheumatological conditions but felt less confident in prescribing rheumatological drugs. Most trainees were confident in performing knee injection and aspiration. The trainees were satisfied with educational and clinical supervision, learning environment and availability of training opportunities. However both trainees and trainers were dissatisfied with inadequate formal teaching and underutilisation of specialty and multidisciplinary clinics. Rota gaps and excessive workload were thought to be the main barriers.

Conclusions: In a climate of increasing service demands, limited time and manpower shortage, training junior doctors effectively has become more challenging An effective induction, supportive learning environment, structured training with incorporated formal teaching would help optimise the learning opportunities.

\section{REFERENCES:}

\section{Arthritis}

Research UK National Primary Care Centre, Keele University. Musculoskeletal Matters: what do general practitioners see? Bulletin 1, October 2009. www.keele. ac.uk/media/keeleuniversity/ri/primarycare/bulletins/MusculoskeletalMatters1.pd

[2] General Medical Council (2016). Promoting excellence: standards for medical education and training. www.gmc-uk.org/education/standards.asp (accessed 31 Oct 2017).

[3] Creswell JW, Plano Clark, VL. Designing and Conducting Mixed Methods Research. Thousand Oaks, CA: Sage, 2007.

[4] Braun, V. \& Clarke, V. Using thematic analysis in psychology. Qualitative Research in Psychology 2006;3(2): 77-101.

[5] Dubey SG, Roberts C, Adebajo AO, Snaith ML (2004). Rheumatology training in the United Kingdom: the trainees' perspective. Rheumatology;43:896-900
[6] General Medical Council. National Training Surveys. 2017 National training survey results live reporting tool. October 2017. https://webcache.gmc-uk. org/analyticsrep/saw.dll?Dashboard. (accessed 31 Oct 2017).

[7] General Medical Council National Training Survey. 2017 http://www.gmc uk.org/education/surveys.asp https://webcache.gmc-uk.org/analyticsrep/ saw.dll?Dashboard (accessed 31 Oct 2017).

Disclosure of Interest: None declared

DOI: 10.1136/annrheumdis-2018-eular.1187

\section{AB1383 RHEUMATOLOGY NURSES KNOWLEDGE AND CONFIDENCE IN THE EVER-CHANGING RHEUMATOLOGY -A REGIONAL SURVEY AMONG EAST MIDLANDS RHEUMATOLOGY SPECIALIST NURSES}

T. Dorman, M. Attwal, J. Sabu, A. Moorthy. University Hospitals of Leicester NHS trust, Leicester, UK

Background: Rheumatology as a specialty moving rapidly due to the advent of novel therapeutic agents. Rheumatic Disease management concepts are also changing with a treat to target approach and early escalation of therapies. Role of Rheumatology specialist nurses should not be underestimated in the tight control and achieve treat to target goals. The expectation of Specialist Nurse role has been changed over the years. NHS pressure in service delivery compromised teaching and training opportunities for Specialists Nurses which may result in the knowledge gap. Education and training for Rheumatology nurses are key in delivering high-quality service to rheumatology patients. We attempted to explore the current knowledge and skills among Rheumatology specialist nurses regionally.

Objectives: 1To explore the knowledge perception of different disease management

2. To identify the difference in two disease management RA and Spondyloarthropathy( $\mathrm{SpA})$.

3. To evaluate the confidence level in assessing different Rheumatic diseases Methods: This is a Questionnaire based prospective study among east midlands Rheumatology Specialist Nurses. The initial questionnaire was piloted and improved 17 questionnaires were distributed among the specialist nurses working in our region via email and in person. The questions were designed to gauge the nurses level of confidence in assessing different rheumatology conditions and also their confidence in making treatment decisions for different conditions.

Results: 26 out of 40 nurses in East Midlands responded with response rate of $65 \%$. $77 \%$ Reponses are from nurses working in University hospitals and $23 \%$ working from DGH. The level of experience in current role is variable from 2 to 20 Year and clinical session performed by nurses varies from 2-8 per week. The nurses are mostly supervised by consultant and some do independent clinic. The awareness of delay in diagnosis of Spa is about $80 \%$ with average reported delay as 6 years. Confidence in assessing RA is very good however not confident in assessing SLE. Confidence level in counselling biologic therapy varies with different diseases with SLE been very low. SpA assessment with extra articular management is low and less confidence in advising therapy in Pregnancy. Interesting note the awareness concept of Non-Radiographic Spa and MRI protocols in Spa Confidence is exists. Variable level of confidence in the in assessment of various diseases. Confidence in assessing Fibromyalgia in a patient with Rheumatic dis ease is at a low level.

Conclusions: we noted the very good level of confidence in RA and PSA assessment and management however low levels of confidence in the assessment of SLE and SpA. More education and training is needed particularly focused on assessment. This is the first study among Rheumatology Specialist Nurses with limitations. Education and training through continuous Medical education for Rheumatology nurses are key to achieve tight control of Rheumatic diseases, reduce the morbidity and Mortality.

\section{REFERENCE:}

[1] Solomon DH, Bitton A, Fraenkel L, Brown E, Tsao P, Katz JN. Roles of nurse practitioners and physician assistants in rheumatology practices in the US. Arthritis Care Res 2014 Jul;66(7):1108-13.

Acknowledgements: 1. All East Midlands Nurses who completed this regiona survey.

Disclosure of Interest: None declared

DOI: 10.1136/annrheumdis-2018-eular.5924 